\title{
Territorialidade quilombola e trabalho: relação não dicotômica cultura e natureza
}

\author{
Maria Sueli Rodrigues de Sousa ${ }^{1,2}$ \\ http://orcid.org/0000-0003-4611-2262
}

\author{
Joaquim José Ferreira dos Santos² \\ http://orcid.org/0000-0002-6778-1492
}

${ }^{1}$ Universidade Federal do Piauí, Centro de Ciências Humanas e Letras, Departamento de Ciências Jurídicas, Teresina, PI, Brasil

${ }^{2}$ Universidade Federal do Piauí, Centro de Ciências Humanas e Letras, Programa de Pós-Graduação em Sociologia, Teresina, PI, Brasil

Territorialidade quilombola e trabalho: relação não dicotômica cultura e natureza

Resumo: $\mathrm{O}$ artigo traz a discussão sobre trabalho e territorialidade quilombola como processos não dicotômicos se tomada a categoria trabalho como não mediada por proprietários dos meios de produção, em que a relação cultura e natureza ocorre numa dinâmica em que o ser humano faz a si e o meio onde vive e trabalha. A pergunta orientadora é: de que modo a territorialidade quilombola supera a dicotomia cultura e natureza? E é orientado pelo pressuposto de que a superação da relação dicotômica cultura e natureza se dá pela não interferência de proprietários nem da terra nem dos meios de produção na referida relação. O texto está organizado em três partes: a categoria trabalho; as comunidades quilombolas e a apropriação comunal. O texto foi produzido no âmbito de uma pesquisa sobre a constitucionalidade das terras de quilombo e é resultado de pesquisa bibliográfica e documental.

Palavras-chave: Trabalho. Territorialidade quilombola. Propriedade comunal.

\section{Quilombola territoriality and labor: A non-dichotomic relationship between culture and nature}

Abstract: The article presents the debate about labor and quilombola territoriality as non-dichotomous processes when the work category is faced as something unmediated by the owners of the means of production, and where the relationship between culture and nature occurs in a dynamic in which humans make themselves and the environment in which they live and work. The research question is: how does quilombola territoriality overcome the dichotomy of culture and nature? The assumption is that the dichotomic relationship between culture and nature is overcome when there is no interference of owners, land, and means of production in the relationship. The article is organized into three items: work category, quilombola communities, and communal appropriation. The study was produced as part of a research work on the constitutionality of quilombo lands and is the result of bibliographical and documentary analysis. Keywords: Labor. Quilombola territory. Communal property.

Recebido em 31.05.2018. Aprovado em 18.09.2018. Revisado em 26.12.2018.

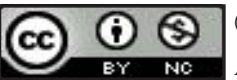

(C) O(s) Autor(es). 2019 Acesso Aberto Esta obra está licenciada sob os termos da Licença Creative Commons Atribuição-NãoComercial 4.0 Internacional (https://creativecommons.org/licenses/by-nc/4.0/deed.pt_BR), que permite copiar, distribuir e reproduzir em qualquer meio, bem como adaptar, transformar e criar a partir deste material, desde que para fins não comerciais e que você forneça o devido crédito aos autores e a fonte, insira um link para a Licença Creative Commons e indique se mudanças foram feitas. 
No final do processo não pode emergir nada que, em seu início, não aparecia como seu pressuposto e condição. Mas, por outro lado, tudo isso tem de emergir. (MARX, 2011a, p. 376).

\section{Introdução}

O artigo 68 do Ato das Disposições Constitucionais Transitórias (ADCT) da Constituição Federal do Brasil (BRASIL, 2001) garante aos remanescentes das comunidades dos quilombos a propriedade definitiva das terras que habitam, cabendo ao Estado emitir-lhes os respectivos títulos.

Como definir o significado e alcance dessas terras? A partir da concepção de Marx sobre a categoria trabalho, defende-se que são terras ocupadas por remanescentes das comunidades dos quilombos - utilizadas para a garantia de sua reprodução física, social, econômica e cultural pelo trabalho, considerando que, para Marx (2013), o trabalho é a condição de existência que conecta corpo e mente, portanto natureza e cultura.

$\mathrm{O}$ texto se propõe a responder de que modo a territorialidade quilombola supera a dicotomia cultura e natureza. E como resposta e pressuposto traz a perspectiva de Marx (2013) que afirma o trabalho como processo entre ser humano e natureza e que a separação entre ambos se dá pela apropriação da força de trabalho pelos proprietários dos meios de produção, condição em regra inexistente na territorialidade quilombola. Portanto, a superação da dicotomia cultura e natureza na territorialidade quilombola se dá em razão da não interferência na dinâmica de trabalho - de modo que pela relação cultura e natureza o ser humano se faz a si pelos modos de criar, fazer e viver - a seus familiares e a própria comunidade quilombola.

Para isso o texto se organiza em três momentos: a discussão sobre a categoria trabalho; exposição sobre as comunidades quilombolas e a apropriação comunal em terras de quilombo. O texto resulta de estudo bibliográfico da obra de Karl Marx, principalmente, O capital (2013); Grundrisse (2011a); e A Ideologia Alemã (MARX; ENGELS, 2011), obras por meio das quais o autor desenvolve a categoria trabalho. A pesquisa também foi feita em comentador da obra de Marx como o inglês David Harvey (2013). Por lei ser documento (Constituição Federal, vulgo CF), trata-se também de uma pesquisa documental. As normas pesquisadas são basicamente os artigos constitucionais que tratam, direta ou indiretamente, dos remanescentes das comunidades de quilombos: art. 216, II e art. 68, do ADCT (BRASIL, 2001).

\section{A compreensão dialética do processo de trabalho}

Segundo David Harvey (2015), diferentemente da categoria valor, produto da era burguesa, portanto, exclusiva do capitalismo, a categoria trabalho poderia se aplicar a todos os modos possíveis de produção. Desta forma, a categoria trabalho, em Marx, é tratada como universal.

O trabalho para Marx (apud HARVEY, 2015, p. 113) é “[...] uma condição de existência do homem, independente de todas as formas sociais, eterna necessidade natural de mediação do metabolismo e, portanto, da vida humana". Ou seja, o trabalho possibilita ao ser humano se construir como tal, uma vez que requer reflexão sobre este agir, e consequentemente, sobre si mesmo.

É através do trabalho que o ser humano apreende a natureza, procura compreendê-la e torna-a aliada da sua luta pela sobrevivência. Ao investir nesta empreitada, planeja a sua atuação, observa, pensa sobre os resultados obtidos. Acertos e erros passam a constituir seu patrimônio de vivência.

Marx (2013, p. 577) ressalta que o ser humano "[...] isolado não pode atuar sobre a natureza sem o emprego de seus próprios músculos, sob o controle de seu cérebro". E para defender seu entendimento de que, nesta situação, não há uma diferenciação entre trabalho intelectual e trabalho físico, Marx (2013, p. 577) lembra que "Assim como no sistema natural a cabeça e as mãos estão interligadas, também o processo de trabalho conecta o trabalho intelectual ao trabalho manual".

Vale considerar a perspectiva cultural dos seres humanos, que o impelem a atuar para além de seus órgãos naturais sem dicotomia natureza e cultura. E, por assim se caracterizar, criam instrumentos de produção, aumentando a capacidade de transformação da natureza (SANTOS, 1984).

Harvey (2015) alerta que na visão de Marx sobre trabalho não há uma dicotomia entre humanidade e natureza, aspecto mental e físico, cultura e natureza, mundo natural e artificial. Não existe, aqui, uma luta entre duas forças (humanidade e natureza) na qual uma deve superar necessariamente a outra.

Esta imbricação entre humanidade e trabalho significa que a categoria trabalho em Marx é construída dialeticamente. Ao transformar o que ocorre ao seu redor, o ser humano transforma-se a si mesmo; e não pode transformar-se a si sem transformar o que se passa ao seu redor: 
James Lovelock, por exemplo, defende com sua hipótese de Gaia que a atmosfera que nos mantém neste exato momento nem sempre existiu; ela teria sido criada por organismos vivos que se alimentavam de metano e produziam oxigênio. A dialética da vida orgânica e sua evolução do mundo natural foi, desde sempre, fundamental. (HARVEY, 2015, p. 114).

Portanto, o ser humano modifica o meio ambiente a fim de que este se torne útil a si, possa-lhe satisfazer suas necessidades. Porém, estas transformações não acontecem ao seu bel prazer. Segundo Marx (2017, p. 233), “[...] os homens não têm o livre-arbítrio de suas forças produtivas - que são à base de toda sua história - porque toda força produtiva é uma força adquirida, o produto de uma atividade anterior".

Há, portanto, um encadeamento de ideias, de pensamentos, através dos quais o agir anterior orienta a próxima atividade. Este aprendizado é adquirido coletivamente no enfrentamento cotidiano às condições adversas que a vida impõe aos indivíduos. Como exemplo do afirmado, George Novack $(2015$, p. 49) expõe que "[...] as mulheres primitivas aprenderam a distinguir as plantas comestíveis das não comestíveis e inclusive transformar raízes venenosas em alimentos, como, por exemplo, a mandioca".

Subentende-se no exemplo citado por Novak que este aprendizado foi lento e doloroso, inclusive com o sacrifício, não intencional, de alguns membros do grupo. Todavia, a capacidade de refletir sobre o seu agir na relação com natureza, permitiu ao ser humano adotar novas práticas, desenvolver técnicas de produção.

Adverte-se que a categoria trabalho, embora seja uma categoria indispensável à compreensão da atividade econômica, não se restringe a esta esfera, referindo-se ao próprio modo de ser dos humanos e da sociedade (PAULO NETTO; BRAZ, 2012, p. 41).

Então, é por meio do trabalho e na procura de apropriar-se da natureza que o indivíduo a transforma constantemente, ao fazê-lo, transforma a si mesmo (DURAND, 2016). Deve-se relembrar que não há trabalho sem reflexão, exigindo, pois, que o ser humano pense sobre as limitações e as vantagens que a natureza lhe oferece.

Marx (2013, p. 255) no livro O capital afirma:

O trabalho é, antes de tudo, um processo entre o homem e a natureza, processo este em que o homem, por sua própria ação, medeia, regula e controla seu metabolismo com a natureza. Ele se confronta com a matéria natural como com uma potência natural [Naturmacht]. A fim de apropriar-se da matéria natural de uma forma útil para sua própria vida, ele põe em movimento as forças naturais pertencentes a sua corporeidade: seus braços e pernas, cabeça e mãos. Agindo sobre a natureza externa e modificando-a por meio desse movimento, ele modifica, ao mesmo tempo, sua própria natureza.

Pode-se afirmar então que é por meio do trabalho que o ser humano atua sobre a natureza, modificando-a de acordo com suas necessidades. Ao fazê-lo, modifica a si próprio, apreendendo, aprimorando, desenvolvendo mecanismos que possam facilitar sua atuação. Com isso, o ser humano começa a elaborar sistematicamente as suas experiências e a dos outros. Porém, este aprendizado ocorre no âmbito dos limites impostos pela natureza.

Para Marx e Engels (2015), inicialmente, o ser humano trabalha de forma instintiva, animalesca, para depois se apropriar da natureza de forma útil e consciente, e que no atual regime de economia capitalista, resta a uns vender sua força de trabalho e a outros serem os proprietários dos meios de produção, em que estes realizam o controle dos que vendem a força de trabalho com o auxílio da episteme cognitiva produzida pela divisão do trabalho.

Vale lembrar que o aumento populacional e a diversificação das necessidades orientadas por uma ontologia de permanente e constante busca pelo aprimoramento em evolução para melhor (KANT, 2003), produziram reflexões que resultaram no desenvolvimento de uma episteme de divisão social do trabalho para orientar pensamento e ação social. No início há uma divisão entre trabalho material e espiritual até atingir uma fase da história, no modo de produção capitalista, em que os indivíduos se encontram divididos em classes: uma detém os meios de produção, a outra classe apenas dispõe da sua força de trabalho.

Esta cisão entre o trabalho e a propriedade dos meios de produção, conforme refere Ruy Moreira (1992), modifica profundamente a relação que o trabalhador possui com a natureza. De acordo com este autor, "[...] o capital necessita operar a radical separação entre trabalhador e a natureza, desfazer violentamente seus vínculos orgânicos com a natureza”. (MOREIRA, 1992, p. 73).

A Constituição Federal (BRASIL, 2001), ao garantir aos remanescentes das comunidades de quilombos a propriedade das terras que ocupam, impede, pelo menos formalmente, que estes vínculos orgânicos que estas comunidades possuem com a natureza sejam rompidos.

A partir dos ensinamentos de Ruy Moreira (1992), pode-se afirmar que a territorialidade regularizada possibilitará às comunidades quilombolas enfrentar os infortúnios da forma que lhes for mais conveniente. 
[...] a terra é a despensa primitiva e o arsenal primitivo. Trabalhando-a, tiram os homens seu sustento e os instrumentos com os quais produzirão meios de subsistência e instrumentos de trabalho novos. A naturezaterra é a condição da produção/reprodução das relações entre os homens. Seu controle é a base do poder sobre os homens. (MOREIRA, 1992, p. 76).

Então, se a natureza-terra representa a condição da produção/reprodução das relações entre humanos, a propriedade das terras poderá permitir a proteção desse modo de vida que é atacado pela especulação imobiliária, pelo agronegócio e pelo latifúndio, pode garantir que as comunidades quilombolas possam preservar os seus modos de criar, fazer e viver numa relação não cindida entre cultura e natureza.

\section{As comunidades remanescentes de quilombos e os seus modos de criar, fazer e viver}

Os quilombos na história do Brasil representam um enfrentamento a uma situação adversa que foi dada aos negros escravizados e aos seus descendentes. No entanto, resistiram e cravaram suas raízes em um lugar, formando grupos familiares com vínculo de parentesco entre si. Ali edificaram cercas reais ou imaginárias, que protegem seus saberes, seus santos, seus lamentos, seus tambores, suas expressões, seus modos de criar, de fazer e de viver. Na adversidade, construíram um saber que é transmitido de geração a geração.

\section{Comunidades quilombolas e sua relação com a abolição e a Lei de Terras}

Vale lembrar que a situação de adversidade vivida pelas comunidades quilombolas do presente tem relação com a forma como foi abolida a escravidão no Brasil. Segundo Florestan Fernandes (1974), a abolição da escravatura se deu numa espécie de acordo para garantir a estrutura senhorial e escravocrata. A Lei de Terras de 1850 fez parte desse acordo. Funcionou o impeditivo para as pessoas em situação de escravidão se tornassem proprietárias de terras no pós-abolição, já que as terras teriam proprietários e as que restassem seriam objeto de compra e venda, portanto fora do alcance daqueles que viriam a se libertar da escravidão.

Esse processo de impedir que ex-escravos se tornassem proprietários de terras, portanto fora do alcance da exploração senhorial é considerado como cativeiro da terra por José de Souza Martins (2010), em que as pessoas deixariam de ser escravizadas pela cor da pele e passariam a ser exploradas por não serem proprietárias de terras. Estava aí a interdição racial tornada interdição social e jurídica, que segundo o autor nasceu com a cessão do tráfico e com este a instauração de um novo regime. O autor cita um parecer do Conselho de Estado de 1842 na fase da gestação da Lei de Terras que deixa enunciada explicitamente a nova interdição, ou seja, a transformação de uma interdição racial, que era a escravidão, numa interdição social que era não ser proprietário de terra:

Um dos benefícios da providência que a Secção tem a honra de propor a Vossa Majestade Imperial é tornar mais custosa a aquisição de terras [...]. Como a profusão em datas de terras tem, mais que em outras causas, contribuído para a dificuldade que hoje se sente de obter trabalhadores livres é seu parecer que d'ora em diante sejam as terras vendidas sem exceção alguma. Aumentando-se, assim, o valor das terras dificultandose, consequentemente, a sua aquisição. (MARTINS, 2010, p. 124).

O documento citado por Martins (2010) desvela a origem do cativeiro da terra como substituição ao cativeiro pelo pertencimento racial, que alcança o imigrante, mas não com a mesma força que atinge o exescravo, considerando o capital cultural existente sobre a inferiorização dos pertencimentos raciais negro e indígena e da supremacia do branco.

O outro dado que atesta o afirmado por Florestan Fernandes (1974) foi a abolição sem nenhuma garantia social para a integração das pessoas que seriam libertas no arcabouço de estado nacional. $\mathrm{O}$ autor considera que a absorção do capitalismo como sistema de relações de produção e de troca na sociedade brasileira não se organizou institucionalmente para se caracterizar como uma sociedade de mercado por manter estruturas econômicas, sociais e políticas do regime colonial com ajustes superficiais em que as referidas estruturas foram moldadas por aquela sociedade numa espécie de reorganização do mercado colonial determinado pelos interesses econômicos da aristocracia agrária.

O processo referido por Florestan Fernandes (1974) resultou em manutenção de requisitos econômicos, sociais, culturais e jurídico-políticos da ordem social escravocrata e senhorial com atendimento parcial e flutuante ao mercado capitalista, de acordo com as conveniências econômicas do corpo social senhorial que forneceu os pontos de partida para a reorganização das relações de produção e de mercado sob estrutura escravista. 
Ainda segundo Florestan Fernandes (1974), a nova-velha ordem foi adaptada numa estrutura social periférica e marginal dependente de outras economias capitalistas com a manutenção da origem colonial, escravocrata e senhorial. Dessa forma, nascia a estrutura das relações de competição, em que os senhores gozam dos privilégios com a manutenção dos fatores de acúmulo de riquezas, prestígio social e poder, com a valorização das relações de parentesco. Portanto, a ordem estabelecida não se alterou em seus fundamentos propriamente societários, as convenções, o código de honra tradicional e os mecanismos de dominação patrimonialista continuaram a determinar as relações sociais.

Florestan Fernandes (1974) refere que tal estrutura resultou numa situação atribuída em que a realidade era mantida, mas era atribuída uma mudança que de fato não mudou estruturalmente. E o direito que serviria para ordenar a nova sociedade se origina no conflito axiológico existente entre as normas ideais e as normas práticas que passam a orientar os papéis sociais configurados em torno da posição do senhor.

$\mathrm{O}$ autor supracitado considera que os senhores do café recapturavam o que havia de essencial nas estruturas arcaicas da grande lavoura e projetavam-se em direção a uma organização institucional como racionalização econômica para o trabalho escravo, tendo como elemento típico a fusão de patrimonialismo com a burocracia de uma pretensa sociedade de mercado que funcionou como fonte de compensação e de suplementação de prestigio perdido com a abolição (FERNANDES, 1974).

Tais efeitos, segundo Florestan Fernandes (1974), não

Assim, se os modos de criar, fazer e viver dos remanescentes das

comunidades de quilombos são patrimônio cultural brasileiro, para salvaguardálos deve-se lhes garantir o território onde estes saberes foram moldados, construídos, processados. introduziam igualdade entre os diversos níveis sociais e tampouco destruíram as bases da estratificação, mas reforçaram a vitalidade das ficções sociais que mantinham velhas representações, posições e papéis sociais, o que quase não alterou a realidade histórica, sendo que os senhores escravocratas e seus herdeiros aceitaram de boa-fé a igualdade fictícia e dela tiraram proveito prático. Uma ficção estruturada na tradição, solidariedade patrimonialista, laços de parentesco e de vassalagem e código de honra provinciano.

Nesse contexto, Florestan Fernandes (1974) considera que a abolição em nada afetou o funcionamento normal do status quo, pelo contrário, fortaleceu-o, mobilizando interesses e lealdades sociais úteis a consolidação da ordem existente, em que os libertos estabeleceram relações não muito diferentes das existentes durante o regime escravocrata, sem abalar fundamentos materiais, jurídicos e políticos, em que o privilégio não aparecia apenas como um valor social, mas passou a funcionar como medidor das vantagens devidas ao grupo dos privilegiados.

As relações de privilégio, segundo Florestan Fernandes (1974), passaram a representar o maior obstáculo à formação de uma autêntica sociedade nacional. Obstáculo este expresso no predomínio dos interesses senhoriais e a hegemonia social da aristocracia agrária que impôs a persistência da escravidão com o não acesso à terra e às oportunidades de acesso a riquezas produzidas com renovação e fortalecimento do status quo ao invés de uma sociedade civil de uma nação, mantendo o sistema axiológico com supremacia dos brancos, a desigualdade entre as raças e a dicotomia entre natureza e cultura nas relações de trabalho com a terra.

Com base nas afirmações do autor supramencionado, consideramos que a estrutura social mantida revela que o abolicionismo não tinha a pretensão de produzir uma sociedade de coassociados e iguais pertencentes, o que resultou num protesto que serviu de elo entre a liberação e o passado escravocrata, sem mudanças sociais, sem transformação das estruturas de poder.

$\mathrm{O}$ autor ainda destaca que o abolicionismo foi limitado tanto no plano ideológico quanto político por manter convencionalismo, solidariedade patrimonialista e liberdade consentida numa espécie de ética senhorial fazendo o espírito de elite orientar o abolicionismo (FERNANDES, 1974).

A abolição produziu uma situação social de total desamparo para os libertos da escravidão com a manutenção da negação de humanidade às pessoas que carregavam o legado da escravidão em forma de racismo. O abolicionismo, portanto, estruturou-se somente para atender o interesse dos brancos, ricos e poderosos, que centravam a abolição apenas na necessidade de retirar os obstáculos à expansão da sociedade de mercado mantida com os privilégios dos brancos, resultando numa competição regulada pelas diferenças de níveis sociais, sem liberdade na forma de relações entre iguais, em que o racismo mantém a ordem senhorial escravocrata. 


\section{As comunidades quilombolas na Constituição Federal do Brasil de 1988 e a categoria trabalho}

A situação herdada da abolição que não extinguiu a ordem senhorial configurou-se em comunidades que já existiam e outras que se fizeram a partir da abolição demarcando territórios pelo uso e ocupação em áreas que não moviam os interesses hegemônicos. E na medida em que esses interesses eram acionados essas populações eram expulsas dessas terras. E saiam em busca de outras. Dinâmica que se manteve até a Constituição Federal de 1988, como legal, e depois disso mantém-se como ilegal em razão da garantia da titulação das terras para quem as ocupava. E desta forma nasceu à legalidade das comunidades quilombolas.

Destaca-se que a maioria das comunidades quilombolas, identificadas pela Fundação Cultural Palmares, vive no espaço rural, embora existam comunidades de quilombos em áreas urbanas (FIDELIS, 2011). Na verdade, estas comunidades ocupam os diversos ecossistemas que compõe o meio ambiente brasileiro, explorando os recursos naturais de seus territórios de maneira deveras diversificada.

A Constituição Federal em seu art. 216 (BRASIL, 2001) estabelece que os modos de criar, fazer e viver dos grupos formadores da sociedade brasileira constitui patrimônio cultural brasileiro, devendo o Poder Público, com a colaboração da comunidade, salvaguardá-los. Portanto, como os remanescentes das comunidades de quilombos são grupos formadores da sociedade brasileira, os modos de criar, fazer e viver destas comunidades devem ser preservados.

Estes modos de criar, fazer e viver representam o conhecimento que as comunidades quilombolas adquiriram sobre si e sobre o mundo exterior. Este conhecimento, segundo a teoria marxista, reflete as condições materiais do meio em que as comunidades vivem e reproduzem suas vidas.

Assim, a natureza dos meios de vida, que precede o próprio conhecimento, limita ou restringe a forma pela qual os seres humanos produzem ou produzirão seus meios de vida (MARX; ENGELS, 2011).

Para Marx (2011b), a natureza humana depende das condições materiais de produção, e em um processo dialético, mediado pelo trabalho, sofre transformações na medida em que estas condições também se modificam.

Não se deve, porém, considerar tal modo de produção de um único ponto de vista, ou seja, a reprodução da existência física dos indivíduos. Trata-se muito mais de uma forma determinada de atividade dos indivíduos, de uma forma de manifestar sua vida, um modo de vida determinado. (MARX; ENGELS, 2011, p. 44).

Para Marx (2011b), portanto, as condições materiais de produção, ao garantir a existência física do ser humano, modificam o modo como esse indivíduo vive e como ele se relaciona como os outros membros do grupo de que faz parte. Há, pois, uma coincidência ou relação entre a maneira como os indivíduos manifestam suas vidas, e o que produzem e o modo como produzem.

O criar, o fazer, e o viver de uma determinada comunidade refletem esta "[...] dialética da transformação" (HARVEY, 2015, p. 114), a materialização de um metabolismo que revela que "[...] as ideias não podem surgir do nada". (HARVEY, 2015, p. 114). Para o autor, "Assim, não há nada estranho em dizer que as ideias surgem da relação metabólica com a natureza material e têm a marca dessa origem". (HARVEY, 2015, p. 115).

Consideremos, p. ex., a relação da arte grega e, depois, a de Shakespeare, com a atualidade. Sabe-se que a mitologia grega foi não apenas o arsenal da arte grega, mas seu solo. A concepção da natureza e das relações sociais, que é a base da imaginação grega, e por isso, da [mitologia] grega, é possível com maquinas de fiar automática, ferrovias, locomotivas e telégrafos elétricos? (MARX, 2011a, p. 91).

Desta feita, os modos de criar, fazer e viver, manifestações da vida dos remanescentes das comunidades de quilombos dependem das condições materiais de produção. Isto porque as ações destas comunidades remanescentes quilombolas não descendem apenas do mundo das ideias, ao contrário, surgem das relações estabelecidas entre eles na produção material de suas existências, em que ideias, ação e natureza se interrelacionam (COLLIN, 2010).

O ponto de partida, "materialista", é certamente que o homem é um ser natural. A organização corporal, as relações com as condições naturais são as "bases naturais" da historiografia. [...] Elas condicionam durante tempo muito longo a vida material e por isso todo o edifício econômico e político que se eleva acima. $\mathrm{O}$ cultivo do arroz ou do trigo dará duas civilizações diferentes. (COLLIN, 2010, p. 87).

É lógico que o cultivo de um ou de outro tipo de grão depende das condições naturais, principalmente, solo e água, com que o indivíduo se depara e de toda uma leitura dos fenômenos meteorológicos que irá regular 
ou administrar o plantio e a colheita, que resultam numa cultura que expressa os vínculos territoriais de uma comunidade. Retirar essas comunidades da territorialidade estabelecida histórica, cultural e politicamente provoca graves danos sociais e ambientais.

A título de exemplo, trazemos aqui as considerações de Almeida (2006, p. 95) em Os quilombos e a base de lançamento de foguetes de Alcântara:

Deslocar compulsoriamente, para o interior do continente, comunidades que se dedicam à pesca marítima $\mathrm{e}$ à coleta de frutos que ladeiam o cordão arenoso das praias, significa destruir seu modus vivendi, inviabilizando sua reprodução social. De igual modo podem ser estendidas as medidas que resultam por separá-las compulsoriamente dos recursos florestais que propiciam a extração da amêndoa de babaçu, da juçara e da coleta de frutos (murici, bacuri, buriti).

O modus vivendi dos remanescentes das comunidades de quilombos se expressa, destarte, nas estratégias que inventaram e que desenvolveram para garantir a sobrevivência do grupo. Desta forma, um quilombo que se encontra em um dos municípios do sertão nordestino possui modos de criar, fazer e viver diversos daqueles que são registrados em uma comunidade quilombola cravada na região amazônica.

Os modos de criar, fazer e viver exprimem o processo lento, histórico que os remanescentes das comunidades de quilombos imprimiram com o meio ambiente e, ao mesmo tempo, as limitações, as barreiras e as possibilidades que este os impôs. Não se vê o quilombola se não se percebe o meio onde ele vive e atua. Seu cheiro, seu corpo, seu caminhar, sua vida carregam o chão por onde trilha, o rio em que banha e os frutos de que se alimenta.

Assim, as terras onde as comunidades dos quilombos exercem suas atividades, possibilitam e ditam quem são esses seres. Delimitar o espaço ou mesmo expulsar o grupo do local em que historicamente construíram e desenvolveram suas vidas significa despojá-los deste saber. E, como salienta Marx e Engels (2011, p. 51), "A consciência nunca pode ser outra coisa que o ser consciente, e o ser dos homens é o seu processo de vida real".

Vale considerar ainda que os modos de criar, fazer e viver foram categorizados a partir da Constituição Federal de 1988 (BRASIL, 2001) como patrimônio cultural imaterial, o que significa as razões para proteger a vinculação territorial das comunidades quilombolas e com isso proteger a relação de trabalho não dicotômica que se expressa entre natureza e cultura.

\section{Apropriação Comunal Quilombola}

Ressalta-se, aqui, que as comunidades quilombolas possuem um jeito diverso de apropriação do ambiente geográfico em que vivem (LITTLE, 2002), caracterizado, principalmente, pela propriedade comum das terras que ocupam. Evidencia, pois, a manutenção das experiências que os negros e as negras escravizados no Brasil trouxeram da África.

O uso comum dos meios de produção e solidariedade no agir coletivo serve de amálgama de onde surge o remanescente de quilombo.

Práticas coletivas e ancestrais do trabalho são mantidas até o presente momento em todas as comunidades pesquisadas. Um dos exemplos de trabalho associado é o Muxirum que consiste em uma ação coletiva mediante a qual, durante a semana, os moradores realizam atividades laborais, como: plantar, carpir, colher, entre outras, na roça de uma pessoa; no outro dia, essa mesma ação ocorre na roça, do outro, e assim por diante. (CAETANO; NEVES, 2015, p. 260).

Os modos de criar, fazer e viver dos remanescentes das comunidades quilombolas, pelo menos em grande parte dela - principalmente aquelas que se encontram na zona rural - estão intimamente ligadas ao cultivo de roças, ao plantio e à colheita de grãos.

Segundo as lições de Juliana Santilli (2005), as comunidades quilombolas construíram com o meio em que se instalaram uma relação peculiar, dominando técnicas de cultivo, armazenamento de água no período de estiagem, caçando e pescando de forma a não extinguir nem colocar em risco as espécies por serem sua garantia de vida e com isso obedecendo aos ciclos de reprodução da vida. Lições que aprenderam com os seus ancestrais que vieram da África para serem escravizados no Brasil.

Por se tratar de um processo, esta relação com o meio onde as comunidades se instalaram revela que estes modos de criar, fazer e viver sofrem modificações, alterações no tempo e no espaço. Ambos estão em uma contínua mudança: os quilombos e suas comunidades (aqui no sentido territorial). 
Terry Eagleton (2011) aponta que os seres humanos não são somente resultados ou produtos dos seus ambientes, da mesma forma que esses ambientes não sofrem alterações ao bel prazer dos interesses dos seres humanos, como se fossem argila para automoldagem. O filósofo e crítico literário britânico anota que "[...] se a cultura transfigura a natureza, esse é um projeto para o qual a natureza coloca limites rigorosos". (EAGLETON, 2011, p. 14).

Portanto, uma comunidade, ao mudar sua atividade produtiva, seja em função do local para onde foram assentados, seja pelas mudanças de clima, vegetação, ou dos insumos (energia e água, principalmente), necessitará de um novo repertório de táticas de sobrevivência, surgindo novos modos de criar, fazer e viver.

Neste sentido, Marx (2011a, p. 56) menciona: "Por isso, quando se fala de produção, sempre se está falando de produção em um determinado estágio de desenvolvimento social - da produção de indivíduos sociais".

Seguindo Diegues (2008), pode-se afirmar que caso uma comunidade quilombola seja expulsa de suas terras, causaria embaraços a ponto de dificultar a existência como um grupo portador de determinada cultura. Isso porque surgirão novas relações, embora impregnadas com aquelas que tiveram no passado, entre a natureza e o ser humano; entre o meio ambiente e os remanescentes das comunidades de quilombos. Quanto mais se diferenciar daquelas relações anteriores, mais estes remanescentes das comunidades de quilombos se distinguirão daqueles outros.

E, como afirma Raymond Williams (2011, p. 48-49), “[...] a coisa mais importante que um trabalhador produz é sempre ele mesmo, tanto na condição específica de seu trabalho quanto na ênfase histórica mais ampla dos homens produzindo-se a si mesmos e a sua história".

Nesta mesma linha de pensamento, pode-se afirmar, categoricamente, que a proteção aos remanescentes das comunidades de quilombos requer a titulação das terras que ocupam. Terras em sentido plural: terra para plantar, cultivar sonhos, esperanças, santos, sons, tambores. Terras que contam suas histórias marcadas por uma resistência coletiva contra a opressão, especialmente, terras para garantir que o trabalho se realize sem provocar separação entre natureza e cultura, que este se realize como de o ser humano fazer a si próprio, seus semelhantes no âmbito de uma comunidade em que criar, fazer e viver faça parte da circularidade da vida.

\section{Considerações finais}

A Constituição Federal do Brasil (BRASIL, 2001) garante aos remanescentes das comunidades de quilombos a propriedade das terras que habitam (art. 68, ADCT). Defende-se que, neste caso, a expressão terras deve ser compreendida como o espaço geográfico que permita aos remanescentes quilombolas reproduzirem-se física, social, econômica e culturalmente, ou seja, que lhes garanta preservar os seus modos de criar, fazer e viver de modo em que natureza e cultura não figurem separadas (art. 216, II).

Uma vez que os modos de criar, fazer e viver refletem ou revelam as relações que os remanescentes quilombolas estabeleceram e estabelecem com a natureza. As águas de um rio serão as fontes de alimentos e de lendas de um quilombo ribeirinho. Nas florestas habitam seres inanimados que infligem medo e plantas que curam e que alimentam os remanescentes das comunidades quilombolas amazônicos.

Se "[...] o sabor do trigo não diz nada sobre quem os plantou [...]" (MARX, 2013, p. 261), o local onde se encontra encravada a comunidade quilombola grita os seus modos de criar, fazer e viver.

Assim, se os modos de criar, fazer e viver dos remanescentes das comunidades de quilombos são patrimônio cultural brasileiro, para salvaguardá-los deve-se lhes garantir o território onde estes saberes foram moldados, construídos, processados.

A produção das ideias e a produção espiritual das comunidades quilombolas revelam o modo como elas trabalham na concepção marxiana do termo: o ser humano transforma-se a partir de sua relação com a natureza.

\section{Referências}

ALMEIDA, A. W. B. Os quilombos e base de lançamento de foguetes de Alcântara. Brasília, DF: Instituto Brasileiro do Meio Ambiente e dos Recursos Naturais Renováveis, 2006.

BRASIL. Constituição da República Federativa do Brasil. 27. ed. atual. e ampliada. São Paulo: Saraiva, 2001.

CAETANO, E.; NEVES, C. E. P. Saberes e produção da vida: contradições, limites e possibilidades expressas pelos trabalhadores e trabalhadoras de comunidades tradicionais de Mato Grosso. Educere et Educare, Cascavel, v. 10, n. 19, p. 255-266, 2015. Disponível em: http://e-revista.unioeste.br/index.php/educereeteducare/article/view/11662/8500. Acesso em: 10 jul. 2017.

COLLIN, D. Compreender Marx. Rio de Janeiro: Vozes, 2010.

DIEGUES, A. C. O mito moderno da natureza intocada. 6. ed. São Paulo: Hucitec, 2008. 
DURAND, J. P. A sociologia de Marx. Rio de Janeiro: Vozes, 2016.

EAGLETON, T. A ideia de cultura. 2. ed. São Paulo: Editora Unesp, 2011.

FERNANDES, F. A revolução burguesa no Brasil. Rio de Janeiro: Zahar, 1974.

FIDELIS, L. Quilombos, agricultura tradicional e a agroecologia: o agroecossistema do Quilombo João Surá sob a ótica da sustentabilidade.

Cadernos CERU, São Paulo, v. 22, n. 1, p. 57-72, 1 jun. 2011. Disponível em: http://www.revistas.usp.br/ceru/article/view/29465/ 31324. Acesso em: 6 jun. 2016.

HARVEY, D. Para entender O capital: livro I. São Paulo: Boitempo, 2015.

KANT, I. A metafisica dos costumes. Bauru: Edipro, 2003.

LITTLE, P. E. Territórios sociais e povos tradicionais no Brasil: por uma antropologia da territorialidade. 2002. Disponível em: https:/ /acervo.socioambiental.org/acervo/documentos/territorios-sociais-e-povos-tradicionais-no-brasil-por-uma-antropologia-da. Acesso em: 6 jun. 2016.

MARTINS, J. de S. O cativeiro da terra. 9. ed. rev. e ampliada. São Paulo: Contexto, 2013.

MARX, K. Carta a Pável V. Annenkov - (em Paris). Germinal: Marxismo e Educação em Debate, Salvador, v. 9, n. 2, p. 232-240, ago. 2017. Disponível em: https://portalseer.ufba.br/index.php/revistagerminal/article/viewFile/23640/14896. Acesso em: 26 dez. 2018.

MARX, K. Grundrisse. São Paulo: Boitempo, 2011a.

MARX, K. Miséria da filosofia. São Paulo: Martin Claret, $2011 \mathrm{~b}$.

MARX, K. O capital: crítica da economia política: Livro I: o processo de produção do capital. São Paulo: Boitempo, 2013.

MARX, K.; ENGELS, F. A ideologia alemã. São Paulo: Martin Claret, 2011.

MARX, K.; ENGELS, F. Manifesto do Partido Comunista. Rio de Janeiro: Companhia das Letras, 2015.

MOREIRA, R. O que é geografia. São Paulo: Brasiliense, 1992.

NOVACK, G. As origens do materialismo. São Paulo: Sundermann, 2015.

PAULO NETTO, J.; BRAZ, M. Economia política: uma introdução crítica. São Paulo: Cortez, 2012.

SANTILLI, J. Socioambientalismo e novos direitos: proteção jurídica à diversidade biológica e cultural. São Paulo: Peirópolis, 2005.

SANTOS, T. dos. Forças produtivas e relações de produção: ensaio introdutório. Rio de Janeiro: Vozes, 1984.

WILLIAMS, R. Cultura e materialismo. São Paulo: Editora Unesp, 2011.

\section{Maria Sueli Rodrigues de Sousa}

mariasuelirs@ufpi.edu.br

Doutorado em Direito, Estado e Constituição pela Universidade de Brasília (UnB)

Professora Associada I do Departamento de Ciências Jurídicas e do Programa de Pós-Graduação em Sociologia do Centro de Ciências Humanas e Letras da Universidade Federal do Piaú (UFPI)

\section{Joaquim José Ferreira dos Santos}

joacafs@gmail.com

Bacharelado em Direito pela Universidade Federal do Piauí (UFPI)

Mestrando do Programa de Pós-Graduação em Sociologia do Centro de Ciências Humanas e Letras da Universidade Federal do Piauí (UFPI)

\section{UFPI}

Campus Universitário Ministro Petrônio Portella, s/n - Ininga

Teresina - Piauí - Brasil

CEP: 64.049-550

\section{Agradecimentos}

A todas as comunidades quilombolas encravadas em solo piauiense.

\section{Agência financiadora \\ Não se aplica.}

\section{Contribuições dos autores}

Por ter sido escrito a quatro mãos, a autora e o autor contribuíram com $50 \%$ cada.
Aprovação por Comitê de Ética e consentimento para parti-
cipação Não se aplica por se tratar de pesquisa bibliográfica e documental em textos de lei.

Consentimento para publicação

Não se aplica.

Conflito de interesses

Não há conflito de interesses. 